\title{
The rôle of planetaria: The Library of Alexandria Planetarium Science Center
}

\author{
Hoda S. El-Mitaky \\ Planetarium Science Center, Library of Alexandria, \\ El Shatby, Alexandria 21526, Egypt \\ email: hoda.elmikaty@bibalex.org
}

\begin{abstract}
In ancient times the stars and the Moon were humans' only guide to cross the seas and explore the depths of the deserts. With the use of modern technological gadgets, and the increasingly light pollution, citizens of the world stopped looking at the heavens. How can planetaria play a rôle in reviving public interest in astronomy? How can the beauty of astronomy play a rôle in luring the youth to pursue a career in science? How can astronomy play a rôle in raising public awareness about preserving the environment? Moreover, how can astronomy play a rôle in the dialogue among civilisations?
\end{abstract}

Keywords. Planetaria, culture, education

\section{Introduction}

It has been 400 years since Galileo Galilei first looked in his telescope to map the heavens and confirm the revolutionary theory that the Sun is the centre of our solar system and not planet Earth. The story of Galileo and his endeavour to bring the truth out to the masses still inspires planetarium visitors to this date.

\section{Planetaria around the world can play an important rôle in science education}

"Education is the most powerful weapon which can be used to change the world." Nelson Mandela

Planetaria are endowed with the facilities that enable them to attract audiences with different backgrounds and different age groups and make them look up to the sky and observe: the very first step of the scientific method. Through the various activities in and around different planetarium live/animated shows, the visitors are introduced, in a subtle and studied manner, to the various elements of the modern scientific method. After all, education today is not about a specific problem, but more about a methodology that can be applied to all.

The Planetarium Science Center (PSC) at the Library of Alexandria hosts several events and activities to introduce the visitors to the method of science:

- During the 2005 centennial of Einstein "Miraculous year" of 1905, the Planetarium Science Center at the Library of Alexandria organised an international conference with Nobel Laureates such as Murray Gell-Mann, Klaus von Klitzing and Douglas Osheroff, who addressed the public and introduced them to Einstein's theories in a simple and easy to relate to manner. 
- During the total solar eclipse that occurred to the West of Egypt in 2006, the planetarium at the Library of Alexandria organised a school of astronomy, where 40 selected university students from Egypt and Arab countries participated in a two week session and round-table discussions with professors from MIT (Edmund Bertschinger), Stanford University (Roger Blandford), Max-Planck-Institute for Astrophysics (Simon White), Caltech (Shri Kulkarni) and more. The school ended in a trip to Al-Saloum in the northern coastof western Egypt to observe the eclipse.

- Eratosthenes, the third director of the ancient Library of Alexandria, a scholar, a geographer, a mathematician and astronomer; managed through observation and using simple trigonometric equations to measure the circumference of the Earth with an amazing accuracy. We repeat this experiment every year with school students on the day of the Summer solstice on June 21 using simple equipment and the video conferencing facility to compare measurements with students in Aswan (Upper Egypt) and elsewhere in the world (France, Argentina, USA). Again the scientific method is highlighted in this experiment.

- Various observation camps and hands-on workshops do play a vital rôle in educating youth and in attracting public's attention not only to the beauty of astronomy, but to the importance of science in today's world.

The InterAcademy council report of 2004 entitled Inventing a better future stated that "Enhancing Science and Technology capacity in the developing nations is truly a necessity and not a luxury".

\section{Planetaria and environmental awareness}

Through the planetarium shows children and visitors become more familiar with our universe and with the solar system. They get a clear perspective of our real place in the Universe and the impact, whether positive or negative, humans can have on their environment.

Light pollution is the prime environmental issue that is discussed regularly in almost all planetaria. When the visitors enter the planetarium theater and the lights are put off and the theater dome is lit up with stars: the message is clear.

Regular observation camps in the depth of the desert and in remote coastal areas conducted by the Planetarium's astronomy experts at the Library of Alexandria, allows the youth to not only appreciate the beauty of the skies, but also the nature of Egypt's environment geologically and culturally.

Observation camps in remote areas allow visitors to experience the degree of pollution there is in the cities and they can be guided to the effect this may have on climate change.

Most planetarium visitors learn that:

- Humankind shares the same resources and that we have to join hands to ensure their sustainability;

- We have to talk to each other and work with each other to ensure a better future for the next generation;

- We have to respect and celebrate our diversity.

\section{Planetaria and intercultural dialogue}

History is very important in order to understand where we are and to study where we are going. At the ancient Library of Alexandria, which vanished around 1600 years ago, a marriage existed between Greek and Egyptian Science with some Asian elements added. 
The ancient Library of Alexandria produced, then, an explosion of knowledge unmatched in history:

- Aristarchus (310-230 BCE), first introduced the heliocentric theory at the ancient Library.

- Hipparchus in the 2nd century BCE, calculated the length of the year to within 6.5 minutes, compiled the first known star catalogue and made an early formulation of trigonometry.

- Eratosthenes was the third director of the ancient Library, and brought Archimedes to the Library, gave Callimachus the task to catalogue the scrolls at the Library. He was the father of geography.

- Claudius Ptolemy (65-125) wrote the Almagest. Euclid wrote his elements of geometry.

Arabs and Muslims then revived the flame and they embarked on a major translation effort. Khalif El Al-Ma'amoun established Beit al Hikma and gave an enormous support for learning and in 70 years Arabic would become the language of learning.

From the 9th to 13th century Arab scholars emerged like Jabir Ibn Haiyan (Geber, chemistry, died in 803); Ali Ibn Rabban Al-Tabari (Medicine, mathematics, calligraphy, 838-870); Al-Razi (Rhazes, Medicine, ophthalmology, smallpox, chemistry, astronomy, 864-930); Al-Farabi (Al Pharabius, sociology, logic, philosophy, political science, music, 870-95); Abu Al-Qasim Al-Zahravi (Albucasis, surgery, medicine, 936-1013).

From the 10th to 13 th century from Persia (Iran) and Iraq:

- Muhammad Al-Buzjani (Mathematics, astronomy, 940-997);

- Abu Raihan Al-Biruni (Astronomy, mathematics, determined Earth's circumference, 973-1048);

- Ibn Sina (Avicenna, Medicine, philosophy, mathematics, astronomy, 986-1037);

- Omar Al-Khayyam (Mathematics, poetry, 1044-1123);

- Nasir Al-Din Al-Tusi (Astronomy, non-Euclidean geometry, 1201-1274);

- Al Khwarizmi (Algebra and algorithms, distinguished mathematician and astronomer);

- Ibn Al Haytham (c 965-1040, born in Basra, but made his career in Cairo, where he supported himself copying scientific manuscripts. Among his original works, only those on optics, astronomy, and mathematics survived. His Optics, which relied on experiment rather than on past authority, introduced the idea that light rays emanate in straight lines in all directions from every point on a luminous surface. Sight occurs when the ray hits the eye. On Taking Evidence Over Authority, he wrote: "He who searches for truth is not he who reviews the works of the ancients ... [it is] he who follows argument and evidence, not the statement by an individual, who is inevitably affected by context and imperfection". His work influenced Kepler and Descartes. In his Optics he provided a detailed analysis of the eye, coupled with light rays entering the eye, and gave his optics a very modern twist.

Although Arabs and Muslims made major discoveries and contributions, they did not provide an alternative model to the Ptolemaic one, as Copernicus did. The scientific endeavor does not belong to any single civilisation or religion, it is a universal quest that is built upon through different eras by different cultures and civilisations each adding its own unique input. 


\section{Conclusion}

Planetaria around the world have a responsibility not only to engage the public in the science of astronomy, but to use their facilities to spread the message of science and to raise the public awareness towards issues that impact our everyday life in which the environment is the most crucial.

Most importantly, planetaria should try to promote intercultural dialogue through films and live shows that they introduce to their audience. After all, we all share the same skies and every civilisation has added to our understanding of the skies.

In this domain we, the planetarium specialists, should join hands to work together on various projects and activities that will allow us to fulfill this goal.

Only through science will we have a future for the next generation for the New World. Only through science can we achieve the Millennium Development goals of which goal \#1 is eradicating poverty and hunger.

\section{References}

Al Zarkali 1992, Al- $^{c}$ Alam (Beirut: Dar El Ilm Lilmalayin)

Marcus, S.J. 2004, Inventing a better Future: A Strategy for building Worldwide Capacities in Science and Technology (Amsterdam: InterAcademy Council)

Serageldin, I. 2007a, Inventing our future: Essays on Freedom, Democracy and Reform in the Arab World (Alexandria: Bibliotheca Alexandrina)

Serageldin, I. 2007b, Science: The Culture of Living Change (Alexandria: Bibliotheca Alexandrina) 